\title{
AS MEMÓRIAS E A H(h)ISTÓRIA DO ANO DA MORTE DE RICARDO REIS
}

\author{
Amanda L. Jacobsen de Oliveira ${ }^{1}$ \\ Juliana Prestes de Oliveira ${ }^{2}$
}

\begin{abstract}
RESUMO: Este trabalho busca identificar a construção da história e da memória de Portugal durante o governo de Salazar, a partir do romance $O$ ano da morte de Ricardo Reis (1984), de José Saramago.Os períodos históricos constituídos pela repressão de um governo opressor com frequência fornecem material fértil para as artes; e não poderia ser diferente com a Literatura. A maioria das nações tem algo a contar com respeito ao assunto, sendo que a Literatura pode, então, auxiliar na construção dessa memória histórica e, porque não, discursiva.
\end{abstract}

Palavras-chave: Memória; História; Literatura; $O$ ano da morte de Ricardo Reis; Pós-modernismo.

\begin{abstract}
This work identifies Portugal's history and memory construction during Salazar's governance, from José Saramago's $O$ ano da morte de Ricardo Reis (1984) novel. The historical periods of repression from an oppressor government frequently provide productive subjective matter to the Arts; and it could not be different with Literature. Most nations have something to tell about this subject and, therefore, Literature can help in the construction of this historical and (why not?) discursive memory.
\end{abstract}

Key-words: Memory; History; Literature; $O$ ano da morte de Ricardo Reis; Post-modernism.

\section{INTRODUÇÃO}

A literatura é reconhecida por envolver em seu emaranhado de textos uma infindável rede de ficções e histórias. Contudo, é importante lembrar que, além das estórias fictícias, os textos literários também abrangem uma parcela considerável da História que, normalmente, é relatada pelos historiadores.

Além disso, alguns momentos e fatos históricos se mostram especialmente circunstanciais como temas para a literatura. Como exemplo, podemos lembrar das situações

\footnotetext{
${ }^{1}$ Mestra em Letras Literatura pelo PPGLetras da Universidade Federal de Santa Maria (UFSM/RS), doutoranda em Letras, na linha de pesquisa Literatura, cultura e interdisciplinaridade, pela mesma instituição e bolsista CAPES/DS.

${ }^{2}$ Mestra em Letras Literatura pelo PPGLetras da Universidade Federal de Santa Maria (UFSM/RS), doutoranda em Letras, na linha de pesquisa Literatura, cultura e interdisciplinaridade, pela mesma instituição e bolsista CAPES/DS.
} 
em que as nações e a população sofreram com um governo ou algum outro tipo de poder opressor, passando por uma época de exceção. Dessa forma, quando pensamos em ditadura, podemos lembrar das inúmeras obras que trazem o entrelaçamento da ficção e da história e que nos auxiliam na compreensão, por meio de uma perspectiva diferente da pertencente ao discurso oficial, sobre os acontecimentos, vivências, forma de pensar e governar da época em que reinava a ditadura.

Nesse caso, o texto aqui descrito, busca abordar o romance $O$ ano da morte de Ricardo Reis, do escritor português José Saramago, publicado primeiramente em 1984. Como objeto de estudo, esse romance se mostra pertinente, tendo em vista que o seu tempo ficcional se desenvolve no ano 1936; ano em que o governo de Salazar vigorava em Portugal, e em que a população, consequentemente, sofria com a repressão do poder. Para isso, o texto inicia-se primeiramente com a abordagem do texto ficcional em si, para, posteriormente, pontualmente explicitar alguns excertos nos quais a influência da ditadura é revelada através da trama textual. E, assim, se efetiva o objetivo da pesquisa de mostrar as confluências existentes entre literatura e historiografia através do texto literário.

Buscou-se, também, identificar, através do viés do Pós-modernismo, as releituras históricas e metalinguísticas empreendidas pelo autor em sua obra; tendo em vista que, a partir dessas estratégias, o autor envolve o leitor em seu jogo literário, constituindo uma literatura que procura revelar o leitor a si mesmo, ao mesmo passo em que traz à tona as várias facetas discursivas antes afastadas do discurso oficial. Destarte, permite-se a investigação de uma Literatura problematizadora, que intenciona desestabilizar não só o leitor, mas também a história e a sociedade.

\section{1936 - O ano da morte de Ricardo Reis}

Ao falarmos de literatura em tempos sociais e históricos de repressão, devemos perceber que ela é, também, registro e construção histórica, assim como os livros de História e discursos documentais. No entanto, é sempre importante ter em conta as suas características e estratégias particulares, pois “[...] a literatura mistura continuamente o mundo real e o mundo 
possível: ela se interessa pelos personagens e pelos acontecimentos reais" (COMPAGNON, 2012, p. 133), e os entrelaça com a sua construção ficcional.

Dessa forma, obras como $O$ ano da morte de Ricardo Reis $(1984)^{3}$ podem revelar como o texto metalinguístico pode trazer à tona as relações entre história e literatura. E, para nos dirigirmos ao estudo da obra, devemos, primeiramente, dar atenção ao seu enredo.

Ricardo Reis, na realidade, era um heterônimo do poeta - também português Fernando Pessoa. Como o poeta faleceu sem ter dado fim à vida de seu heterônimo Reis, Saramago toma desse espaço para estabelecer sua narrativa. A partir disso, após a morte de Fernando Pessoa, Ricardo Reis teria retornado a sua terra natal - Portugal - e lá, encontra justamente o fantasma de Fernando Pessoa. Apesar de ser exposto, diariamente, à situação histórica do país - Saramago insere seus personagens no Portugal da década de 1930, que enfrentava o governo autoritário de António Salazar -, Reis se mantém a parte dos acontecimentos, apenas, como ele mesmo diz "observando o espetáculo do mundo". Desse modo, o texto se utiliza da História não como foco, mas como peça de seu quebra-cabeça narrativo, pois ao passo em que narra a história de Ricardo Reis, Saramago também revisita a história de Portugal, sendo que a identidade do país se desenvolve paralelamente à do personagem.

À medida que os personagens circulam nesse ambiente criado pelo ditador, principalmente Ricardo Reis, nos são apresentados os mais diversos pontos de vistas sobre os acontecimentos. Dentre eles, está a visão de Reis, que não sabe nem entende a situação do país, e busca, através dos jornais e de suas conversas com Pessoa, compreender aquela atual Lisboa; a de Lídia, camareira de um hotel que se relaciona com o protagonista e revela sua opinião muitas vezes baseada no que lhe conta o irmão marinheiro e opositor ao governo; a do Dr. Sampaio, pai de Marcenda, advogado hospedado no hotel de Reis, que é favorável ao governo; a falta de posicionamento de Marcenda, que pode estar relacionada ao silêncio do povo português. A partir desses posicionamentos, somos levados a refletir sobre a História de Portugal e podemos aproximá-la da situação brasileira no tempo da Ditadura de 1964.

Através de seu enredo ficcional, este romance de Saramago mescla o discurso histórico e o literário, algumas vezes de uma maneira mais implícita, nas entrelinhas da

\footnotetext{
${ }^{3}$ Para a elaboração deste trabalho foi utilizado a edição de 2001.
} 
discussão sobre os acontecimentos históricos, outras vezes de modo mais explícito, deixando clara a opinião dos personagens e, talvez, do próprio autor. Tal afirmação é perceptível, por exemplo, quando os personagens Fernando Pessoa e Ricardo Reis debatem o efeito que os regimes opressores podem causar nos textos, tanto em relação à escolha dos temas, quanto em relação à questão da censura oficial aplicada às obras entendidas como ameaças ao governo: “[...] aqueles intelectuais que se sentem encarcerados nos regimes de força, mesmo quando essa força é mental, como a que dimana Salazar, esquecem-se de que a produção intelectual se intensificou nos regimes de ordem" (SARAMAGO, 2001, p. 333). O texto saramaguiano, assim, não só faz literatura como pensa sobre esse fazer em condições de cerceamento da liberdade.

Com tal afirmação sugere-se também que quanto maior a opressão, maior a rebeldia, ainda que essa rebeldia precise, para ganhar voz, burlar as imposições da censura. Para os intelectuais, a escrita é uma ferramenta de denúncia, um modo de trazer à tona, através das entrelinhas, partes da $(\mathrm{H})$ história que, na maioria das vezes, são suprimidas pelos discursos oficiais, além de ser uma maneira de manifestar descontentamento.

Ademais, assim como a História se constrói, muitas vezes, por meio de testemunhos, no romance, a história também pode se edificar através da memória. É o que acontece quando Ricardo Reis está caminhando pelas ruas, tentando reconstruir a sua terra natal a partir de suas memórias, e verificando se essas correspondiam à realidade: "Veio por estar tão perto e para verificar, de caminho, se a antiga memória da praça, nítida como uma gravura a buril, ou reconstruída pela imaginação para assim o parecer hoje, tinha correspondência próxima na realidade material" (SARAMAGO, p. 34).

No entanto, nesse caso, ao tentar estabelecer a relação entre a versão do lugar que Reis reconhecia na memória e a versão material - tida como real, dentro do romance - o texto revela que "o testemunho é, ao mesmo tempo, o ponto fraco do estabelecer da prova documental", pois "[é] sempre possível opor os testemunhos uns aos outros, quer no que diz respeito aos fatos relatados, quer no que respeita à fiabilidade das testemunhas". E, por isso, "[u]ma parte importante da batalha dos historiadores para o estabelecimento da verdade, nasce da confrontação dos testemunhos, principalmente dos testemunhos escritos" (RICOEUR, 2003). 
Como os testemunhos são recuperados não somente pelo discurso oral, mas também através de outras ferramentas, como os jornais, por exemplo, o autor também os envolve em sua ficção. O faz, principalmente, nos vários momentos em que o protagonista recorre ao texto jornalístico, para ter conhecimento a respeito dos acontecimentos nacionais e mundiais: "Vai Ricardo Reis aos jornais, vai aonde sempre terá de ir quem das coisas do mundo passado quiser saber" (SARAMAGO, 2001, p. 35). Esse excerto é, então, especialmente interessante, se tomarmos atenção à utilização da palavra 'passado'. Normalmente, o foco de público receptor de jornais seria considerado como o seu contemporâneo, que os lê diariamente ou semanalmente. Contudo, nesse caso, temos os jornais como registro histórico, pois trata-se de "quem das coisas do mundo passado quiser saber".

Outro momento que pode ser citado como exemplo dos jornais como registro histórico é quando algumas famílias da Espanha chegam ao hotel onde Reis está hospedado: "[...] três famílias espanholas [...] vêm fugidas [...] por causa de terem os comunistas ganho as eleições [...] Até os jornais falam disso" (SARAMAGO, 2001, p. 156).

Destarte, com a presença da historiografia nesse texto ficcional, incluindo ainda a menção ao discurso jornalístico, percebemos que há uma relação substancial entre história e ficção, sendo que elas "[...] se articulam como campos discursivos solidários, que narram a experiência humana com imaginação, reflexão e pleno exercício da linguagem" (MILTON, 2012, p. 10).

Ademais, é tomando o discurso dos jornais que Saramago traz a presença do governo de Salazar:

Dizem também os jornais, de cá, que uma grande parte do país tem colhido os melhores e mais abundantes frutos de uma administração e ordem pública modelares [...] sobre o ditador de Portugal, já sobredito, chamando-nos de afortunadíssimos por termos no poder um sábio [...]. Salazar é o maior educador do nosso século (SARAMAGO, 2001, p. 86).

E ainda acrescenta:

Se estas são as mágoas de uma pessoa, a Portugal, como um todo, não faltam alegrias. Agora se festejaram duas datas, a primeira que foi do aparecimento do professor António de Oliveira Salazar na vida pública, há oito anos [...], para salvar o seu e o nosso país do abismo, para o restaurar, para lhe impor 
uma nova doutrina, fé, entusiasmo e confiança no futuro, [...] e a outra data que também diz respeito ao mesmo senhor professor, sucesso de mais íntima alegria [...], que foi ter completado, logo no dia a seguir, quarenta e sete anos de idade, nasceu no ano em que Hitler veio ao mundo e com pouco diferença de dias, vejam lá o que são coincidências, dois importantes homens públicos (SARAMAGO, 2001, p. 298-299).

Devemos notar que os elogios dedicados a Salazar são frutos do discurso dos jornais. Portanto, isso revela o financiamento das mídias por parte do governo e do poder, o que mostra, como comentado previamente, a instabilidade do testemunho, que é influenciado pela posição dos escritores e meios de divulgação. Sendo assim, ao passo em que:

[A] historiografia [...] vasculha o passado dando-lhe contornos visíveis e demonstráveis; a literatura, quando o enuncia, empreende a simbolização das referências oriundas da pesquisa histórica, podendo inclusive desestabilizálas no âmbito da invenção poética (MILTON, 2012, p. 10).

Portanto, essa desestabilização demonstra não só a instabilidade do testemunho, como também dos discursos, sendo ele histórico ou literário. Há, assim, uma relativização da construção da verdade, levando em conta que essa é sempre constituída com a utilização da linguagem.

Carlos Reis, professor da Universidade de Coimbra, analisa a relação existente entre História, ficção e pintura, sendo o diálogo que ele traça entre História e ficção o mais pertinente para o estudo aqui apresentado. Para Carlos Reis (2015), através da ficção e da pintura ocorre uma "leitura" da verdadeira $(\mathrm{H})$ história, por meio do questionamento do discurso oficial. Também observa como ocorre a figuração dos personagens e diz que “[...] o movimento de figuração confirma a relevância das personagens como imagens para uma releitura" (REIS, 2015, p. 40) dos acontecimentos, feita a partir do que o romance apresenta. Reis ainda acrescenta: “[...] trata-se de uma leitura da leitura da História, pois que ele se centra num romance que só o foi a partir da pesquisa meta-historiográfica que o escritor José Saramago levou a cabo" (REIS, 2015, p. 40).

Baseado nessas ideias, Reis apresenta seus pensamentos sobre como a literatura é um veículo de conhecimentos de épocas. Como ela pode fazer isso sem estar necessariamente apegada a dados verídicos, ela permite se elaborar por meio de fatores que o discurso 
científico não utiliza. Além disso, o autor discorre sobre o modo como a literatura desafia as visões que a $(\mathrm{H})$ história apresenta e como a ficção de Saramago interpela e refigura a $\mathrm{H}(\mathrm{h})$ istória através de seus personagens. Indo ao encontro das ideias da literatura ser um meio de acessar testemunhos e os acontecimentos nos tempos de exceção.

Outrossim, Saramago leva a condição da linguagem mais a fundo, quando trata do seu papel e da sua utilização em tempos de regimes de repressão, como no caso da época vivida por Ricardo Reis: "aqueles intelectuais que se sentem encarcerados nos regimes de força, mesmo quando essa força é mental, como a que dimana Salazar, esquecem-se que a produção intelectual se intensificou sempre nos regimes de ordem" (SARAMAGO, 2001, p. 333). Dessa forma, mostra que, apesar de constituir tempos de opressão, a ditadura civil e militar também é um momento que impulsiona a proliferação artística, principalmente na literatura. Entretanto, ainda assim, o autor não nega o silenciamento provocado por tais regimes, como quando o sugere, através do seguinte trecho: "Alguém transporta ao colo uma criança, que pelo silêncio portuguesa deve ser" (SARAMAGO, 2001, p. 13).

Devemos prestar atenção ao fato de que, o que caracteriza a criança como portuguesa, é justamente o seu silêncio, o que, então, possivelmente, revela a condição vivida na época pelo povo português. Desse modo, há não só a constituição da identidade da nação portuguesa, como também de seu povo, sendo que esse silêncio é provocado por alguma força - principalmente ideológica - provinda do poder. Como pode ser observado a seguir: "agora a sala está silenciosa, nem as crianças levantam as vozes, estranho caso, Ricardo Reis não se lembra de as ter ouvido falar, ou são mudas, ou têm os beiços colados, presos por agrafes invisíveis" (SARAMAGO, 2001, p. 26). Não só as crianças são então mudas, mas também toda a população, diante do governo opressor.

A partir dessas artimanhas e ironias narrativas com as quais Saramago envolve o leitor, podemos notar que

[s]em lugar a dúvidas, a disciplina histórica é filão inesgotável para a invenção poética, instituindo-se como uma plataforma de signos sobre a qual a narrativa literária engendra seus vastos mundos. Por outro lado, é indiscutível que as criações ficcionais também servem como testemunhos de épocas para a interpretação histórica e que, entre os dois universos, cada qual orientado por suas próprias leis, impõem-se canais de negociação que se abrem ao estabelecimento de múltiplos sentidos (MILTON, 2012, p. 10). 
E esses múltiplos sentidos se dão, necessariamente por essa relação mútua, onde, através de característica da historiografia, a literatura consegue estabelecer a sua ficção e a relativização das narrativas; e a História, por sua vez, pode se utilizar do discurso literário para considerar as diferentes interpretações de eventos históricos. E, como acrescenta o próprio Saramago, citado por Heloisa Milton:

[...] a História se apresenta como parente próxima da ficção, dado que, ao rarefazer o referencial, procede a omissões, portanto a modificações, estabelecendo assim com os acontecimentos relações que são novas na medida em que incompletas se estabeleceram (SARAMAGO, apud MILTON, 2012, p. 9).

Sendo assim, no decorrer do caminho realizado com a leitura do texto de Saramago, acompanhado das considerações históricas, singularmente no que diz respeito à ditadura civil e militar, atenta-se aos significados que a história e a literatura podem inferir em seus contextos, a partir das lacunas (não de sentido pejorativo) que ambas permitem, mutuamente, aos seus textos.

No decorrer da narrativa, Saramago reflete sobre o fazer literário, o modo de se produzir um texto literário e de fazer arte num contexto repressivo. O jogo literário efetuado por ele é ainda mais profundo quando percebemos que seus livros podem também evocar, além da época vivida pelos personagens, a época do próprio escritor. De fato, pressupõe-se, nas entrelinhas narrativas, questionamentos ao regime opressor vivido pelo país ou que estava passando à época da escritura de $O$ ano da morte de Ricardo Reis. É flagrante, no texto, enfim a relação entre o ficcional e o histórico, assumindo, predominantemente, um tom reflexivo acerca dos acontecimentos do passado e da atualidade.

José Saramago discorre sobre as potencialidades de intervenção da literatura na sociedade:

[a] literatura pode muito pouco. Não vamos embarcar em ilusões, no otimismo. Ajudar a humanidade? Não sei se a humanidade quer ser ajudada. Mas a missão do escritor, se existe alguma, é não se calar, que deveria ser a missão de todas as consciências (SARAMAGO, 2010, s. p.) 
A partir disso, percebemos a posição de Saramago em relação ao papel dos escritores diante dos acontecimentos que os cercam. Estes podem se utilizar da escrita para expor aqueles fatos que o discurso oficial ou dominante procura camuflar ou não deixa vir à tona. Algo evocado no romance $O$ ano da morte de Ricardo Reis, e que nos permite a reflexão sobre a relação entre Literatura e História, e as denúncias acerca dos regimes opressores advindos desse relacionamento.

\section{Referências}

COMPAGNON, Antoine. O demônio da teoria: Literatura e senso comum. Tradução: Cleonice Paes Barreto Mourão e Consuelo Fortes Santiago. 2. ed. 1. reimp. Belo Horizonte: UFMG, 2012. 292 p.

MILTON, Heloisa Costa. Prefácio: A literatura lê a história, a história não deixa de ler a literatura. In: FIORUCI, Wellington Ricardo; FIORUCCI, Rodolfo. (Org.). Vestígios de memória: diálogos entre literatura e história. Curitiba: CRV, 2012, p. 9-14.

REIS, Carlos. Figurações da personagem: a ficção meta-historiográfica de José Saramago. Revista Estudos Saramaguianos, v.1, n. 1, p. 38-51, 2015. Disponível em: <https://drive.google.com/file/d/0BxyJDvv3PhxmZWMyVDlnQjg0SEE/view?pli=1>. Acesso em: 23 mar. 2015.

RICOEUR, Paul. Memória, história, esquecimento. Budapeste, 8 mar. 2003. Palestra.

SARAMAGO, José. O ano da morte de Ricardo Reis. São Paulo: Companhia das Letras, 2001.

Entrevista com José Saramago. Entrevistador: JÚNIOR, Antônio. In: LEAL, Bruno. Blog Café História. [S. 1.], 2010. Disponível em:

<http://cafehistoria.ning.com/profiles/blogs/jose-saramago-entrevista>. Acesso em: 22 jan. 2015. 